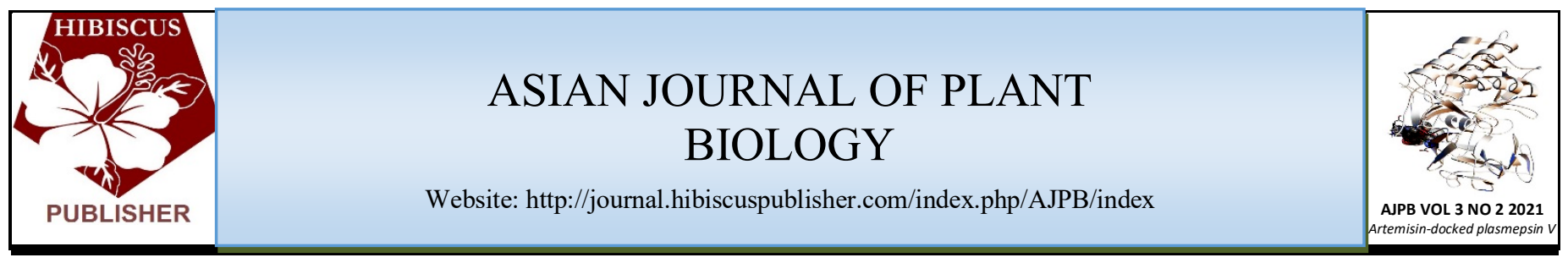

\title{
Isothermal Modelling of the Adsorption of Cibacron Blue onto Bean Peel
}

\author{
Shukor, M.Y. ${ }^{1}$ \\ ${ }^{1}$ Department of Biochemistry, Faculty of Biotechnology and Biomolecular Sciences, \\ Universiti Putra Malaysia, 43400 UPM Serdang, Selangor, D.E, Malaysia. \\ *Corresponding author: \\ Prof Dr. Yunus Shukor, \\ Department of Biochemistry, \\ Faculty of Biotechnology and Biomolecular Sciences, \\ Universiti Putra Malaysia, \\ 43400 UPM Serdang, \\ Selangor, D.E, \\ Malaysia. \\ Email: yunus.upm@gmail.com / mohdyunus@upm.edu.my
}

\section{HISTORY}

Received: 23rd Oct 2021

Received in revised form: $24^{\text {th }}$ Nov 2021

Accepted: $15^{\text {th }}$ Dec 2021

\section{KEYWORDS}

Biosorption

Cibacron Blue

Bean peel

Isotherm

Langmuir

\begin{abstract}
Biosorption is a sort of sorption technology in which the sorbent is a substance that is biologically sourced. In today's world, biosorption is seen as a simple, inexpensive, and ecologically friendly way for removing pollutants from the environment. One of the branches of bioremediation that is utilised to decrease environmental pollution in the context of minimising improper textile waste disposal is this method. The sorption isotherm of Cibacron Blue onto bean peel were analyzed using ten models - Henry, Langmuir, Dubinin-Radushkevich, Freundlich, BET, Toth, Sips, FritzSchlunder IV, Baudu and Fritz-Schlunder V, and fitted using non-linear regression. Statistical analysis based on root-mean-square error (RMSE), adjusted coefficient of determination $\left(\operatorname{adj} R^{2}\right)$, bias factor (BF), accuracy factor (AF), corrected AICc (Akaike Information Criterion), BIC and HQC showed that the Freundlich model was the best model in terms of overall best criteria. The calculated evidence ratio was 8 with an AICc probability value of 0.89 indicating that the best model was at least 8 times better than the nearest best model, which was Sips. The calculated Freundlich parameters $K_{F}$ (Freundlich isotherm constant) and $n F$ (Freundlich exponent) were $5.369(\mathrm{~L} / \mathrm{g})(95 \%$ confidence interval from 4.359 to 6.379$)$ and 3.125 (95\% confidence interval from 2.717 to 3.533 ). The Langmuir constant was utilized to calculate the maximum adsorption capacity $Q_{m L}(\mathrm{mg} / \mathrm{g})$ which gave a value of $27.83 \mathrm{mg} / \mathrm{g}(95 \%$ confidence interval from 23.69 to 31.98). The nonlinear regression method allows for the parameter values to be represented in the $95 \%$ confidence interval range which can better allow comparison with published results.
\end{abstract}

\section{INTRODUCTION}

Humans have been fascinated by colour for centuries, whether from an aesthetic or a social one. More than a century has passed since dyes and pigments were recognised as the primary source of creative resources. A significant growth in the dyeing industry's need for synthetic pigments has occurred in recent decades, owing to the cheap cost of synthetic pigments, their availability in a wide range of colours, and the simplicity with which they may be manufactured. There are thousands of different tints available on the market, with around 7105 tonnes of tint being manufactured yearly. Beginning in 2017, Malaysia has been one of the country's major manufacturers in the textile business. The technique, as a consequence, poses a substantial danger of contaminating groundwater since it results in the loss of up to 280,000 tonnes of dyes every year. It is textile waste that is the most serious polluter of clean water, and it is dyeing and finishing methods that are to fault (Kant, 2011). Dissolved oxygen, a key resource for aquatic life, has been reduced in the water as a result of excessive dye discharge. Because of this, the ecology has suffered a huge setback. Depletion will also have an adverse effect on the capacity of water bodies to self-clean. According to Kant (2012), in order to keep pollutants under control throughout the dyeing and finishing process, an environmentally friendly method must be implemented to replace the hazardous steps that are now used (Wong et al., 2020).

Textile dye run-offs must be minimised because of the threats they represent to the environment and the health of the general population. Because of the rise in textile manufacturing, the danger of excessive dye pollution of the water system is increasing. Dyeing and finishing technology, as we all know, is the most significant source of textile waste and the most significant source of water contamination. With the poor 
effectiveness of typical wastewater treatment comes the issue of excessive release of unresolved colourants into the environment, which may be harmful to human health. During the textile manufacturing process, a significant amount of water is used in the dyeing and finishing stages. According to the amount and nature of textile effluents emitted, textile effluents are the most environmentally harmful industrial wastewater. Textile dyes ultimately made their way not just into freshwater systems, but even into marine systems (Slama et al., 2021). Depending on the colour used, between 2 and $40 \%$ of the dye was released into the environment as wastewater. Biosorption processes are particularly significant in a variety of biotreatment processes, including environmental and conventional biotreatment. In order to remove or recover organic or inorganic stuff from solution, biological materials such as live or dead microbes and their constituents, marine algae, plants, agricultural wastes, and naturally-produced inhabitants are designed to do so.

The precise assignment of biosorption kinetics and isotherms is critical for understanding the process of biosorption in these species. In many cases, the literature reports a linearized version of an obviously nonlinear curve of these data. Nonlinear data linearization distorts the data's error structure, making it more difficult to assess uncertainty, which is often displayed as a 95 percent confidence interval range [1]. In this study the published data from a Cibacron Blue onto bean peel is remodeled with several more isotherms models (Table 1) and then regressed using nonlinear regression method and assessment of the best mode was carried out using various error function analysis.

Table 1. Isotherm models utilized in this study.

\section{METHODS}

\section{Data acquisition and fitting}

Data from Figure 1 from a published work [12] were digitized using the software Webplotdigitizer 2.5 [13]. The data were then nonlinearly regressed using the curve-fitting software CurveExpert Professional software (Version 1.6). Digitization using this software has been acknowledged for its reliability $[14,15]$.

\section{Statistical analysis}

A battery of statistical discriminatory tests such as corrected AICc (Akaike Information Criterion), Bayesian Information Criterion (BIC), Hannan and Quinn's Criterion (HQ), RootMean-Square Error (RMSE), bias factor (BF), accuracy factor $(\mathrm{AF})$ and adjusted coefficient of determination $\left(R^{2}\right)$ were utilized in this work.

The RMSE was calculated according to Eq. (1), [1], and smaller number of parameters is expected to give a smaller RMSE values. $n$ is the number of experimental data, $O b_{i}$ and $P d_{i}$ are the experimental and predicted data while $p$ is the number of parameters.

$$
R M S E=\sqrt{\frac{\sum_{i=1}^{n}\left(P d_{i}-O b_{i}\right)^{2}}{n-p}}
$$

As $R_{R}^{2}$ Q⿱⿰㇒一十凵 parameters in a model, the adjusted $R^{2}$ is utilized to overcome thris issue. In the equation (Eqns. 2 and 3), the total variance of the $y$-variable is denoted by $S_{y}^{2}$ while RMS is the Residual Mean Square.

$$
\begin{aligned}
& \underset{\text { A3] }}{\text { Adjusted }}\left(R^{2}\right)=1-\frac{R M S}{S_{Y}^{2}} \\
& \text { Adjusteld }\left(R^{2}\right)=1-\frac{\left(1-R^{2}\right)(n-1)}{(n-p-1)}
\end{aligned}
$$

The AIC ${ }^{[5.6} \mathrm{c}$ is calculated as follows (Eqn. 4), where $p$ signifies the quantity of parameters and $n$ signify the quantity of data points. To handle data having a high number of parameters or a smaller numben of values corrected Akaike information criterion (AICc) is utilized [16].A model with a smaller value of AICc is deemed likely more correct [16]. The Akaike Information Criterion (AIC) is bassd on the information theory. It balances between the goodness of fit of a particular model and the complexity of a modelo[17]

$$
q_{e}=\frac{q_{m B E T} \alpha_{B E T} C_{e}}{\left(1-\beta_{B E T} C_{e}\right)\left(1-\beta_{B E T} C_{e}+\alpha_{B E T} C_{e}\right)}
$$

$$
\underset{[10]}{A I C c=2 p+n \ln }\left(\frac{R S S}{n}\right)+2(p+1)+\frac{2(p+1)(p+2)}{n-p-2}
$$$$
\text { [11] }
$$

Aside from AICc, Bayesian Information Criterion (BIC) (Eqn. 5) is another statistical method that is based on information theory. This error function penalizes the number of parameters more stttbngly than AIC [18]. 
$B I C=n \cdot \ln \frac{R S S}{n}+k \cdot \ln (n)$

(Eqn. 5)

A further error function method based on the information theory is the Hannan-Quinn information criterion (HQC) (Eqn. 6). The HQC is strongly consistent unlike AIC due to the $\ln \ln n$ term in the equation [16];

$H Q C=n \times \ln \frac{R S S}{n}+2 \times k \times \ln (\ln n)$

(Eqn. 6)

Further error function analysis that originates from the work of Ross [19] are the Accuracy Factor (AF) and Bias Factor (BF). These error functions test the statistical evaluation of models for the goodness-of-fit but do not penalize for number of parameter (Eqns. 7 and 8).

Bias factor $=10^{\left(\sum_{i=1}^{n} \log \frac{\left(P d_{i} / O b_{i}\right)}{n}\right)}$

(Eqn. 7)

Accuracy factor $=10^{\left(\sum_{i=1}^{n} \log \frac{\left|\left(P d_{i} / O b_{i}\right)\right|}{n}\right)}$

(Eqn. 8)

Another error function analysis is the evidence ratio regarding the difference between the two lowest AICc values (Eqn. 9), where if it is the same, then each model will have an equal chance of being true. If the difference in AICc scores is 6.0, model A has a $95 \%$ chance of being correct, making it $20(95 / 5)$ times more likely than model B to be correct [1].

$P_{A}=\frac{e^{0.5 \Delta}}{1+e^{0.5 \Delta}}$

(Eqn. 9)

\section{RESULTS AND DISCUSSION}

The equilibrium data from [12] was analyzed using ten modelsHenry, Langmuir, Dubinin-Radushkevich, Freundlich, BET, Toth, Sips, Fritz-Schlunder IV, Baudu and Fritz-Schlunder V, and fitted using non-linear regression (Figs. 1-8) Statistical analysis based on root-mean-square error (RMSE), adjusted coefficient of determination $\left(\operatorname{adj} R^{2}\right)$, bias factor $(\mathrm{BF})$, accuracy factor (AF), corrected AICc (Akaike Information Criterion), BIC and HQC showed that the Freundlich model was the best model in terms of overall best criteria (Table 2). The calculated evidence ratio was 8 with an AICc probability value of 0.89 indicating that the best model was at least 8 times better than the nearest best model, which was Sips.

The calculated Freundlich parameters $K_{F}$ (Freundlich isotherm constant) and $n F$ (Freundlich exponent) were 5.369

$(\mathrm{L} / \mathrm{g})(95 \%$ confidence interval from 4.359 to 6.379$)$ and 3.125 (95\% confidence interval from 2.717 to 3.533$)$. In the published work, the Freundlich parameters $K_{F}$ and $n F$ values of $4.965(\mathrm{~L} / \mathrm{mg})$ and 0.3418 were obtained [12], which showed a large difference in value for $n F$. The Langmuir constant was utilized to calculate the maximum adsorption capacity $Q_{m L}$ $(\mathrm{mg} / \mathrm{g})$ which gave a value of $27.83 \mathrm{mg} / \mathrm{g}$ (95\% confidence interval from 23.69 to 31.98 ).
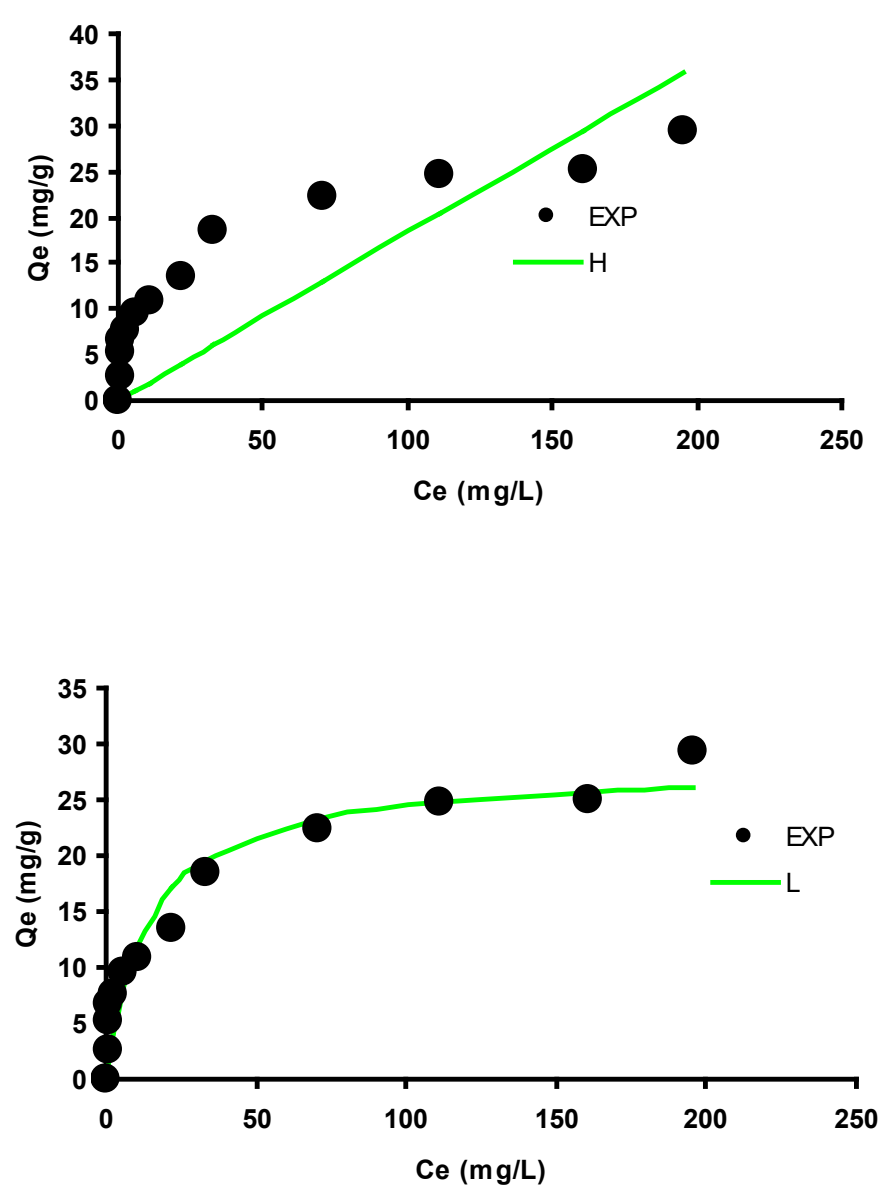

Fig. 2. Biosorption isotherm of Cibacron Blue onto bean peel as modelled using the Langmuir model.

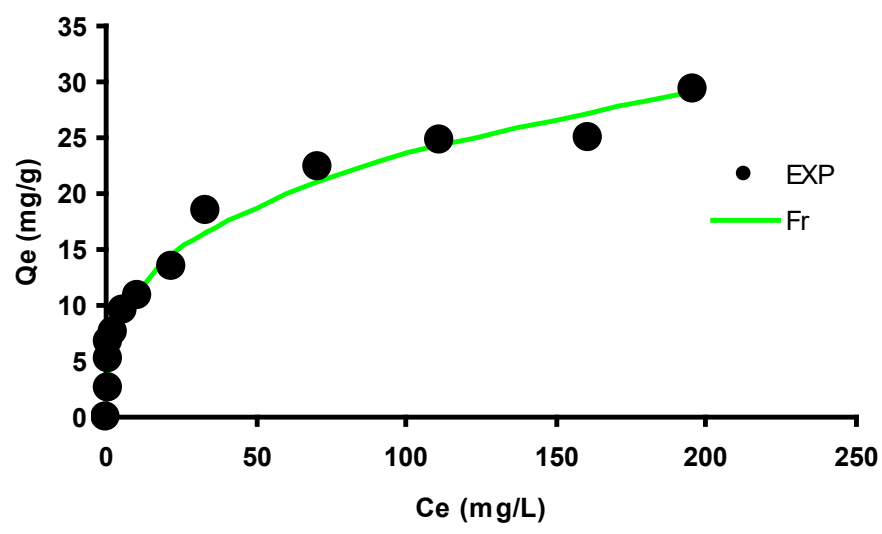

Fig. 3. Biosorption isotherm of Cibacron Blue onto bean peel as modelled using the Freundlich model. 

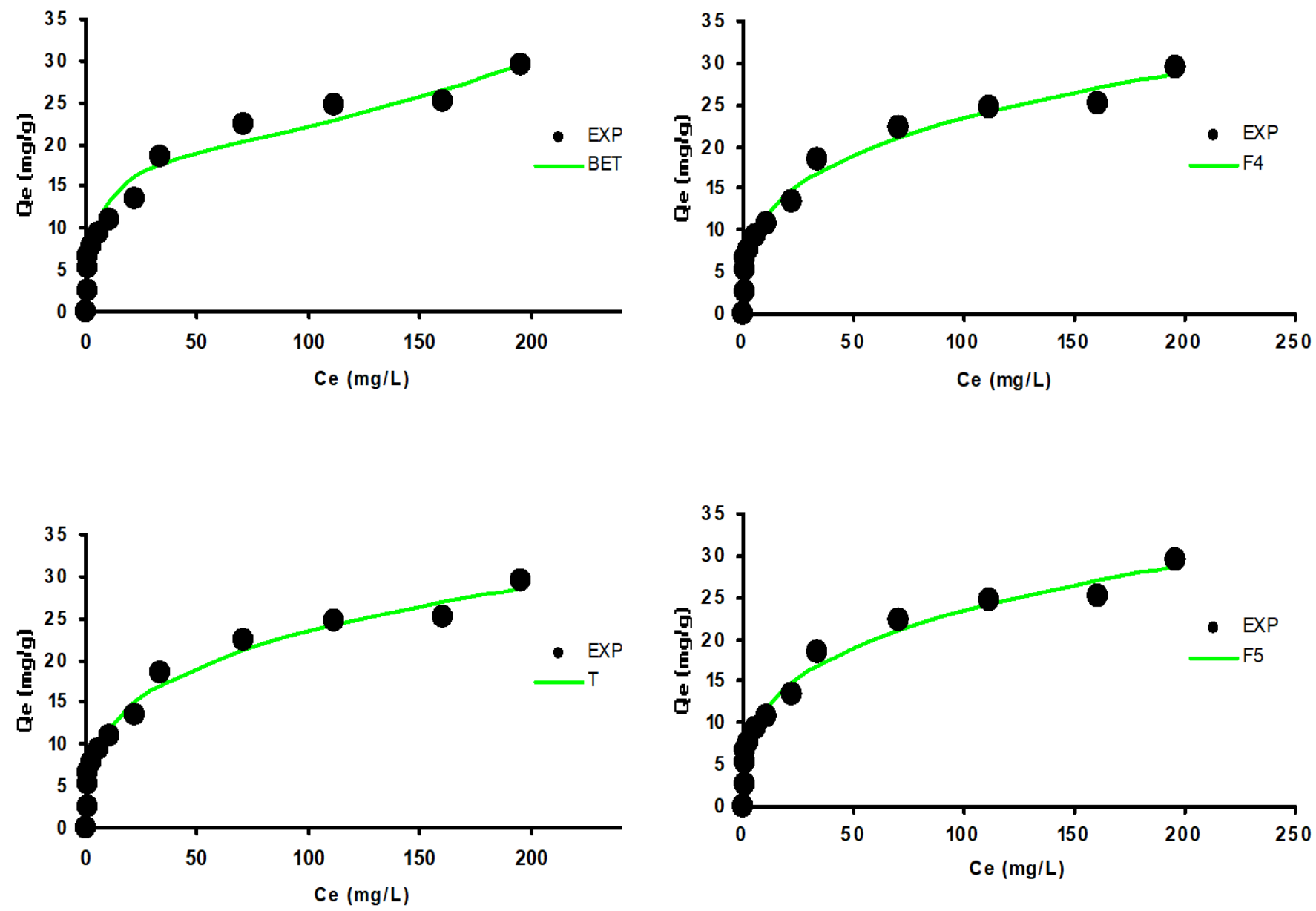

Fig. 8. Biosorption isotherm of Cibacron Blue onto bean peel as modelled using the Fritz-Schlunder V model.
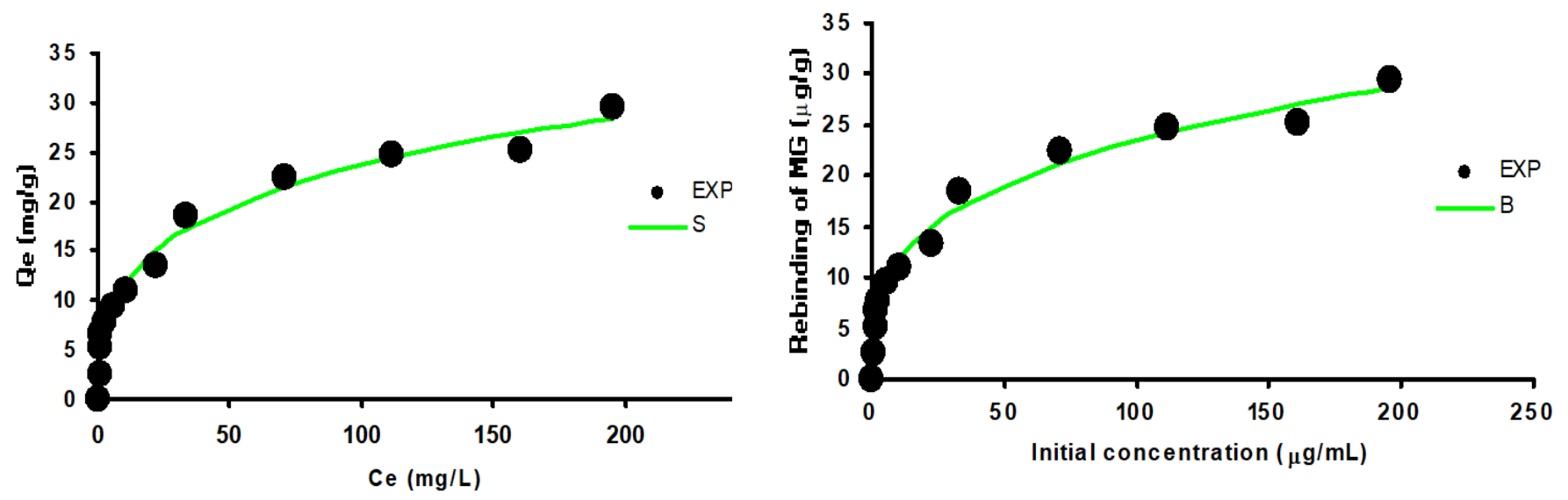

Fig. 8. Biosorption isotherm of Cibacron Blue onto bean peel as modelled using the Baudu model. 
Table 2. Error function analysis for the fitting of the isotherm of Cibacron Blue onto bean peel.

\begin{tabular}{lllllll}
\hline Model & $p$ & AICc & BIC & HQC & BF & AF \\
\hline Henry & 1 & 58.72 & 54.09 & 53.40 & 0.23 & 4.52 \\
Langmuir & 2 & 35.28 & 27.74 & 26.38 & 0.80 & 1.34 \\
Freundlich & 2 & 18.39 & 10.86 & 9.49 & 1.04 & 1.12 \\
BET & 3 & 32.09 & 20.78 & 18.74 & 0.96 & 1.15 \\
Toth & 3 & 22.77 & 11.46 & 9.42 & 1.02 & 1.11 \\
Sips & 3 & 22.64 & 11.34 & 9.29 & 1.02 & 1.11 \\
Baudu & 4 & 27.52 & 11.20 & 8.48 & 1.01 & 1.07 \\
F4 & 4 & 27.14 & 10.83 & 8.11 & 1.01 & 1.06 \\
F5 & 5 & 36.57 & 13.40 & 9.99 & 1.01 & 1.06
\end{tabular}

Note:

RMSE Root mean Square Erro

no of parameters

$\mathrm{adR}^{2} \quad$ Adjusted Coefficient of determination

BF Bias factor

AF Accuracy factor

AICc Adjusted Akaike Information Criterio

BIC Bayesian Information Criterion

HQC Hannan-Quinn information criterio

The Langmuir isotherm is among the most cited best isothermal models to govern biosorption of xenobiotics followed by the Freundlich model [20-27]. The Langmuir model was the best model for the biosorption of Cibacron Blue by inactive mycelial biomass of Panus fulvus [28] while both the Langmuir and Freundlich models were found to be the best for Cibacron Blue sorption by activated sludge [29]. The sorption kinetics reported in this study were within the range of published literature for sorption of Cibacron Blue [12,28-31].

\section{CONCLUSION}

In conclusion, the absorption kinetics data of biosorption isotherm on the biosorption of Cibacron Blue onto bean peel has been successfully analyzed using modelled according to various models ranging from one to five parameters models and fitted using non-linear regression. Statistical analysis based on rootmean-square error (RMSE), adjusted coefficient of determination $\left(\operatorname{adj} R^{2}\right)$, bias factor $(\mathrm{BF})$, accuracy factor $(\mathrm{AF}), \mathrm{BIC}, \mathrm{HQC}$ and corrected AICc (Akaike Information Criterion) showed that the Freundlich model was the best. The calculated Freundlich parameters $K_{F}$ (Freundlich isotherm constant) and $n F$ (Freundlich exponent) showed a large difference in value for $n F$ from the original publication. The Langmuir constant was utilized to calculate the maximum adsorption capacity $Q_{m L}$ $(\mathrm{mg} / \mathrm{g})$ which gave a value of $27.83 \mathrm{mg} / \mathrm{g}$ (95\% confidence interval from 23.69 to 31.98 ).

\section{REFERENCES}

1. Motulsky HJ, Ransnas LA. Fitting curves to data using nonlinear regression: a practical and nonmathematical review. FASEB J Off Publ Fed Am Soc Exp Biol. 1987;1(5):365-74.

2. Ridha FN, Webley PA. Anomalous Henry's law behavior of nitrogen and carbon dioxide adsorption on alkali-exchanged chabazite zeolites. Sep Purif Technol. 2009;67(3):336-43.

3. Langmuir I. The adsorption of gases on plane surfaces of glass, mica and platinum. J Am Chem Soc. 1918;40(9):1361-403.

4. Adamson AW. Physical chemistry of surfaces. New York: UMI; $1993.664 \mathrm{p}$

5. Radushkevich LV. Potential theory of sorption and structure of carbons. Zhurnal Fiz Khimii. 1949;23:1410-20.

6. Dubinin MM. Modern state of the theory of volume filling of micropore adsorbents during adsorption of gases and steams on carbon adsorbents. Zh Fiz Khim. 1965;39(6):1305-17.

7. Sips R. On the structure of a catalyst surface. J Chem Phys. 1948;16(5):490-5.

8. Toth J. State equations of the solid-gas interface layers. Acta Chim Acad Sci Hung. 1971;69(3):311-28.

9. Brunauer S, Emmett PH, Teller E. Adsorption of gases in multimolecular layers. J Am Chem Soc. 1938;60(2):309-19.
10. Baudu M. Etude des interactions solute-fibres de charbon actif Application et regeneration. Universite de Rennes I; 1990.

11. Fritz W, Schluender E-U. Simultaneous adsorption equilibria of organic solutes in dilute aqueous solutions on activated carbon. Chem Eng Sci. 1974;29(5):1279-82.

12. Grabi H, Derridj F, Lemlikchi W, Guénin E. Studies of the potentia of a native natural biosorbent for the elimination of an anionic textile dye Cibacron Blue in aqueous solution. Sci Rep. 2021 May 6;11(1):9705

13. Rohatgi A. WebPlotDigitizer http://arohatgi.info/WebPlotDigitizer/app/ Accessed June 2 2014.; 2015.

14. Halmi MIE, Shukor MS, Johari WLW, Shukor MY. Mathematica modelling of the degradation kinetics of Bacillus cereus grown on phenol. J Environ Bioremediation Toxicol. 2014;2(1):1-5.

15. Khare KS, Phelan Jr FR. Quantitative comparison of atomistic simulations with experiment for a cross-linked epoxy: A specific volume-cooling rate analysis. Macromolecules. 2018;51(2):56475

16. Burnham KP, Anderson DR. Model Selection and Multimodel Inference: A Practical Information-Theoretic Approach. Springer Science \& Business Media; 2002. 528 p.

17. Akaike H. New look at the statistical model identification. IEEE Trans Autom Control. 1974;AC-19(6):716-23.

18. Kass RE, Raftery AE. Bayes Factors. J Am Stat Assoc. 1995 Jun 1;90(430):773-95.

19. Ross T, McMeekin TA. Predictive microbiology. Int J Food Microbiol. 1994;23(3-4):241-64.

20. Pourang N, Rezaei M. Biosorption of copper from aqueous environment by three aquatics-based sorbents: A comparison of the relative effect of seven important parameters. Bioresour Technol Rep. 2021 Sep 1;15:100718.

21. Javed I, Javed T, Khan MN. A characteristic study of Zea mays L. (sweet corn) cobs for synthetic dye degradation from aqueous media. Water Sci Technol. 2021;83(1):52-62.

22. Adenan NH, Lim YY, Ting ASY. Nocardiopsis sp. for the Removal of Triphenylmethane Dyes: Decolorization and Optimization Studies. Water Air Soil Pollut. 2021;232(10).

23. Yahuza S, Sabo IA, Abubakar A, Shukor MY. Biosorption of Lead (II) Ions by Brown Algae: A Thermodynamic Study. Bull Environ Sci Sustain Manag. 2020 Dec 31;4(2):1-5.

24. Scheufele FB, Staudt J, Ueda MH, Ribeiro C, Steffen V, Borba CE, et al. Biosorption of direct black dye by cassava root husks: Kinetics, equilibrium, thermodynamics and mechanism assessment. J Environ Chem Eng. 2020;8(2).

25. Gebrezgiher M, Kiflie Z. Utilization of Cactus Peel as Biosorbent for the Removal of Reactive Dyes from Textile Dye Effluents. J Environ Public Health. 2020;2020.

26. Gupta S, Sharma SK, Kumar A. Biosorption of Ni(II) ions from aqueous solution using modified Aloe barbadensis Miller leaf powder. Water Sci Eng. 2019 Mar 1;12(1):27-36.

27. da Rosa ALD, Carissimi E, Dotto GL, Sander H, Feris LA. Biosorption of rhodamine B dye from dyeing stones effluents using the green microalgae Chlorella pyrenoidosa. J Clean Prod. 2018 Oct 10;198:1302-10.

28. Sathishkumar M, Binupriya AR, Vijayaraghavan K, Yun S-I. Two and three-parameter isothermal modeling for liquid-phase sorption of Procion Blue H-B by inactive mycelial biomass of Panus fulvus. J Chem Technol Biotechnol. 2007;82(4):389-98.

29. Aksu Z. Biosorption of reactive dyes by dried activated sludge: Equilibrium and kinetic modelling. Biochem Eng J. 2001;7(1):7984.

30. de Araújo Padilha CE, da Costa Nogueira C, de Santana Souza DF, de Oliveira JA, dos Santos ES. Organosolv lignin/Fe3O4 nanoparticles applied as a $\beta$-glucosidase immobilization support and adsorbent for textile dye removal. Ind Crops Prod. 2020;146.

31. Ekanayake MS, Udayanga D, Wijesekara I, Manage P. Phytoremediation of synthetic textile dyes: biosorption and enzymatic degradation involved in efficient dye decolorization by Eichhornia crassipes (Mart.) Solms and Pistia stratiotes L. Environ Sci Pollut Res. 2021;28(16):20476-86. 